\title{
MECHANICAL PROPERTIES OF BLAIR DOLOMITE
}

\author{
H. C. Heard
}

A. Duba

A. E. Abey

R. N. Schock

Octobsr 19, 1973

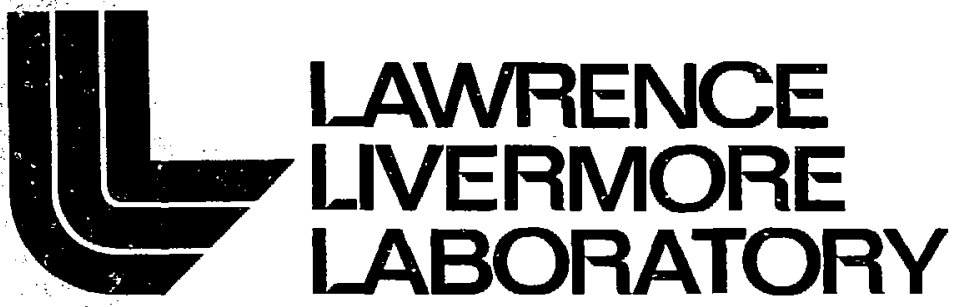

University of California/Livermore 
This report was preparted as an account of rock sponsord by the United Stuts Goxmment. Nelthet the Unitis Stotn not the United Stata Alomis Encrsy Comminion, nor any of their employees, not any of theit conlectors, aubontusctors, or theis employces, makes any wetenly. capress or imptizl, of asumes any $k p l$ liability or texponsibility for the accurany. compkteness or usetutnes of asy informalton, appratus. Moduet or poras dieclosed, of represents that fis use would nol infrinte primlelyowned rights."

\section{Printed in the United States of America Available from \\ National Technical Information Service \\ U.S. Department of Commerce 5285 Port Royal Road \\ Springfield, Virginia 22151}

Price: Printed Copy $\$$; Microfiche $\$ 0.95$

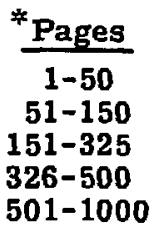

NTIS

Selling Price

$\$ 4.00$

$\$ 5.45$

$\$ 7.60$

$\$ 10.60$

501-1000

$\$ 13.60$ 
TID-4500, UC-11

Environmental and Earth Sciences

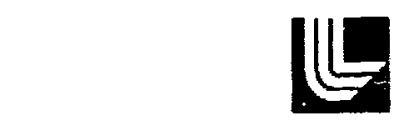

\section{LAWRENCE IMERMOAE LABORATOAY}

Uhiversity or Caftomia Lwomore, Cafiomin 94550

UCRL-51465

\section{MECHANICAL OROPERTIES OF BLAIR DOLOMITE}

H. C. Heard

A. Duba

A. F. Abey

R. N. Schock

MS. date: October 19, 1973

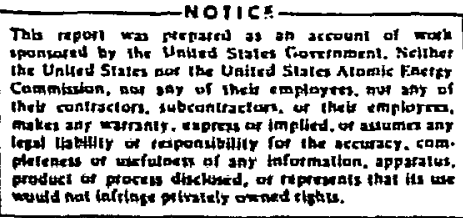

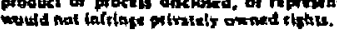




\title{
MECHANICAL PROPERTIES OF BLAIR DOLOMITE
}

\begin{abstract}
Pressure-volume, uniaxial stress loading to failure, uniaxial strain, and acoustic velocity determinations have been made on Blaix dolomite at confining pressures ranging to $3.5 \mathrm{GPa}$. The bulk modulus, $K$, rapidly rises from an initial 10.4 GPa (at atmospheric pressure) to $102.0 \mathrm{GPa}$ at $1 \mathrm{GPa}$ pressure. At higher pressures, $K$ remains essentially constant (110 GPa). The maximum volume change on loading is $3.9 \%$ at $3.5 \mathrm{GPa}$; the unloading closely follows the loading path.

Comparison of uniaxial stress tests in compression to $0.7 \mathrm{GPa}$ and extension to 2.1 GPa confining pressure demonstrates that the characteristic shear stress at failure as well as the transition from brittle fracture to ductile flow is strongly dependent upon both the value of the intermediate principal stress $\sigma_{2}$ and the rate of strain. The onset of dilatancy as determined in uniaxial compression occurs at about two-thirds of the failure stress. The uniaxial strain loading path is well below the failure envelope in compression.

In uniaxial stress loading (compression), Young's modulus $(E)$ and shear modulus $(\mu)$ are demonstrated to be very sensitive to both confining pressure and to the revel of shear stress. For example, at pressures of $0.1 \mathrm{MPa}$ to $0.5 \mathrm{GPa}$, both $\mathrm{E}$ and $\mu$ first increase up to shear stresses of 0.05-0.15 GPa and then decrease at all higher stress values. These moduli are shown to be very sensitive indicators of the onset of dilatancy. Elastic moduli as derived frara acoustic velocity measurements also increase with confining pressure (to $1 \mathrm{GPa}$ ), with the major change occurring below $0.1 \mathrm{GPa}$. All of the observations made at nonhydrostatic conditions are consistent with the closure of pre-exi:iting cracks at low pressures and low shear stresses followed $t_{j}$ an increasing rate of crack growth as stress is increased, even at the higher confining pressures. However, some cracks, which would normally close with hydrostatic pressure, remain oper under uniaxial str $\mathbf{s s}$ loading at similar mean pressures.
\end{abstract}

\section{Introduction}

Accurate prediction of seismic sigmal.s from an underground nuclear explosion requires an understanding of the coupling between the energy released by the device and the surrounding rock. This problem is currently being addressed by both theo- retical and experimental means. In the latter case, material properties are investigated over a range of experimental conditions and the results are combined with model studies. Computer code calculations are then performed to correlate 
these rasults with field tests. This approach necessitates that the behavior of at least 5-10 rock ma' ecials be investigated. The purpose of this report is to summarize our findings on the high-pressure mechanical properties of one rock, Blair dolomite. The types of equation-of-state (EOS) data to be presented include pressure-volume measurements to $3.5 \mathrm{Gr}^{\prime} \mathrm{x}^{*}$ " the shear strength-mean pressure failure envelope as determined in compr $-\operatorname{siun}$ to $0.7 \mathrm{GPa}$

\footnotetext{
In this report we present data in the International System of Units (SI). Pressures and stresses are given in Pascals (Pa), where $10^{5} \mathrm{~Pa}=1$ bar. Thus $100 \mathrm{MPa}=0.1 \mathrm{GPa}=1 \mathrm{kbar}$.
}

and extension to $2.1 \mathrm{GPa}$ pressure. Uniaxial stress loading moduli are shown up to $0.5 \mathrm{GPa}$, and uniaxial strain loadingunloading paths are presented to $0.7 \mathrm{GPa}$ confining pressure. Shear and compressional wave velocities ( $1 \mathrm{MHz}$ ) are determined to 1.0 GPa pressure. The loading rates for all except the latter were $-10^{-4} s^{-1}$.

Blair dolomite is a dark gray, fairly homogeneous, fine-grained, equigranular tolomite $\left[>98 \% \mathrm{CaMg}\left(\mathrm{CO}_{3}\right)_{2}\right]$ from Berkeley Co., West Virginia. The measured density (dry) is $2.84 \mathrm{~g} \cdot \mathrm{cm}^{-3}$, and the calculated porosity is $0.9 \%$, based on the $x$-ray ${ }^{1}$ density of dolomite, 2.866 g $\mathrm{cm}^{-3}$.

\section{Experimental}

The test samples were prepared by coring cylinders from the unoriented dolomite block and facing the ends, normal to the cylinder axis, parallel to $<0.02 \mathrm{~mm}$. Samples were then either air-dried for several weeks or oven-dried at $80^{\circ} \mathrm{C}$ for 4 days: dimensions ranged from 20-30 $\mathrm{mm}$ in diameter by 30-100 $\mathrm{mm}$ in length. Depending on the test type and conditions, these samples were jacketed with thin metal or plagtic sleeves in order to exclude the liquid confining pressure medium from the pores. All measurements discussed below were made on the dry Blair dolomite only.

The experimental techniques and apparatus used for the EOS measurements have been described previously. ${ }^{2-8}$ Quasihydrostatic P-V data on cylindrical samples $(13 \mathrm{~mm}$ diameter $\times 25 \mathrm{~mm}$ ) were obtained to $3.5 \mathrm{GPa}$ in a piston-cylinder device. A soft metal (cin) was used as the pressure-transmitting medium. Pressure-volume data were also obtained to $1.4 \mathrm{GPa}$, using a Muid to transmit hydrostatic pressure to the metal-jacketed samples. Volumetric strains were calculated from readings of foil strain gages cemented to the metal jacket. The assemblies were initially seasoned to 1-3 MPa in order tn shrink the jacket onto the rock sample.

Identically prepared specimens were used in the three-dimensiolal stresastrain experiments where axial load was applied with the piston of a piston-cylinder die in which the hydrostatic pressure could be externally controlled. The uniaxial stress and uniaxial strain data from these experiments were then used to calculate deformation moduli and to determine the loading-unloading paths below the 
compression failure envelope. The shear strergth-mean pressure failure envelope in both compression and extension was determined from a series of differential stress-axial strain measurements on metal-or plastic-jacketed samples.
Acoustic relocities were obtained by meas 4 ring the transit time of a i $\mathrm{MHz}$ plane wave through jacketed samples. Both of these latter types of tests were corrected for the strength of the jacketing materials.

\section{Pressure-Volume Measurements}

The pressure-volume relationship of Blair colornite was measured on five samples all cut from a single core. Tiree samples were tested in the ciasihydrostatic apparatus. One of these was $12 \mathrm{~mm}$ in diameter and was compressed to $3.5 \mathrm{GFa}$, while the other two were $24 \mathrm{~mm}$ in diameter and were tested to $3 \mathrm{GPa}$. The remaining two samples were $24 \mathrm{~mm}$ in diameter and were compressed hydrostatically to a peak pressure of $1.4 \mathrm{GPa}$. All samples tested were $25 \mathrm{~mm}$ in length.
Table 1. Bulk modulus as a function of pressure, dry Blair dolomite.

\begin{tabular}{cc}
$\begin{array}{c}\text { Fressure, } \\
\mathrm{MPa}\end{array}$ & $\begin{array}{c}\text { Bulk modulus, } \\
\text { SPa }\end{array}$ \\
\hline 0.1 & 10.4 \\
200 & 58.0 \\
400 & 74.6 \\
600 & 86.2 \\
800 & 95.0 \\
1000 & 102.0 \\
1200 & 106.0 \\
$1400-3500$ & 110.0 \\
\hline
\end{tabular}

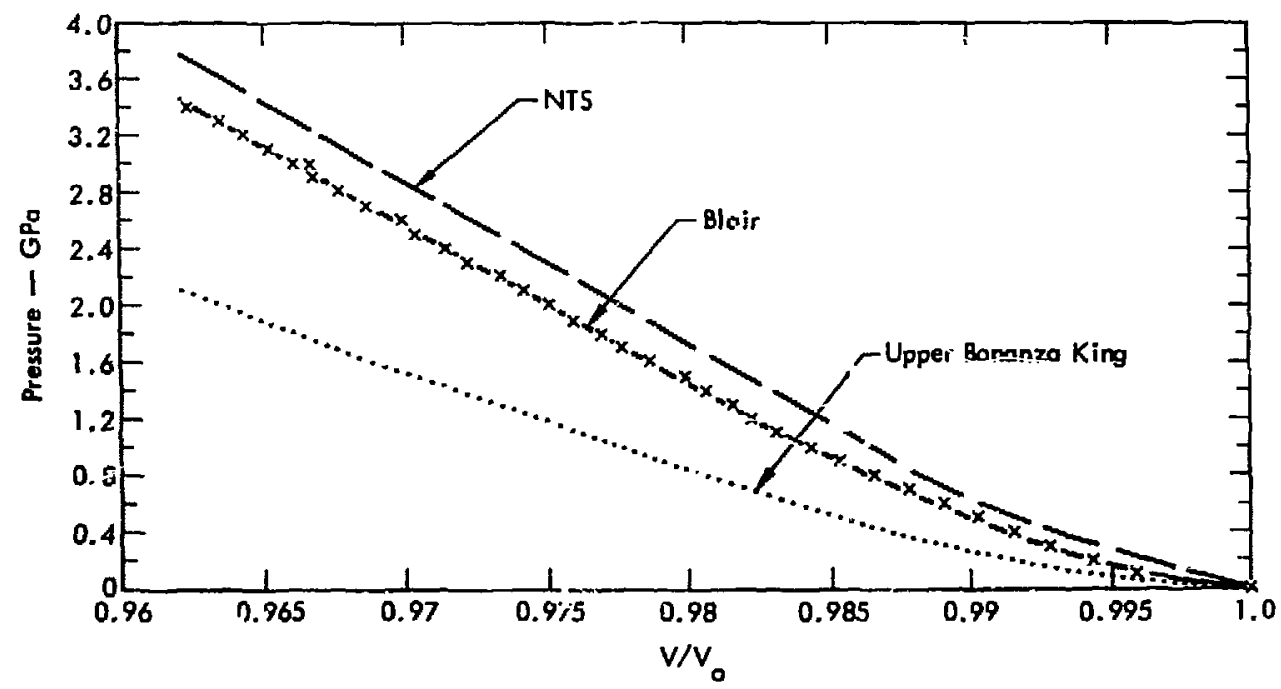

Fig. i. Pressure-volume relationships for dry ilair $\left(\rho_{0}=2.84 \mathrm{~g} \mathrm{~cm}^{-3}\right)$, NTS $\left(\rho_{0}=2.804 \mathrm{~g} \mathrm{~cm}^{-3}\right)$, and Upper Bonanza King $\left(\rho_{0}=2.769 \mathrm{~g} \mathrm{~cm}^{-3}\right)$ dolomites. 
Table 2. Computed velocities and derived elastic moduli for dry Blair dolomite.

\begin{tabular}{|c|c|c|c|c|c|c|c|}
\hline $\begin{array}{c}\text { Pressure, } \\
\mathrm{MPa} \\
\end{array}$ & $\begin{array}{l}\text { Density, } \\
\text { g.cn }-3\end{array}$ & $\begin{array}{l}\text { Compr. } \\
\text { velocity, } \\
\mathrm{km} \cdot \mathrm{s}^{-1}\end{array}$ & $\begin{array}{c}\text { Shear } \\
\text { velocity, } \\
\mathrm{km} \cdot \mathrm{s}^{-1}\end{array}$ & $\begin{array}{c}\text { Bulk } \\
\text { modulus, } \\
\text { GPa }\end{array}$ & $\begin{array}{c}\text { Shear } \\
\text { modulus, } \\
\text { GPa }\end{array}$ & $\begin{array}{c}\begin{array}{c}\text { Poisson's } \\
\text { ratio }\end{array} \\
\end{array}$ & $\begin{array}{c}\text { Young's } \\
\text { modulus, } \\
\text { GPa } \\
\end{array}$ \\
\hline 0.1 & $2.8 j 0$ & 5.02 & 3.02 & 37.4 & 25.9 & 0.22 & 63.1 \\
\hline 10 & 2.851 & 5. 32 & 3.10 & 44.3 & 27.4 & 0.24 & 68.1 \\
\hline 20 & $2.85 i$ & 5.47 & 3.16 & 47.5 & 28.4 & 0.25 & 71.0 \\
\hline 30 & 2.852 & 5.59 & 3.20 & 50.1 & 29.3 & 0.26 & 73.5 \\
\hline 40 & 2.852 & 5.74 & 3.23 & 54.2 & 29.8 & 0.27 & 75.6 \\
\hline 50 & 2.853 & 5.90 & 3.26 & 59.1 & 30.3 & 0.28 & 77.6 \\
\hline 60 & 2.853 & 6.14 & 3.29 & 66.3 & 30.8 & 0.30 & 80.1 \\
\hline 70 & 2.854 & 6.43 & 3.31 & 76.2 & 31.2 & 0.32 & 82.5 \\
\hline 80 & 2.854 & 6.55 & 3.33 & 80.1 & 31.7 & 0.33 & 84.1 \\
\hline 100 & 2.855 & $6.6 \%$ & 3.41 & 83.1 & 33.1 & 0.32 & 87.7 \\
\hline 150 & 2857 & $6.8{ }^{\prime}$ & 3.51 & 88.1 & 35.1 & 0.32 & 93.0 \\
\hline 200 & 2.858 & 7.00 & 3.55 & 92.1 & 36.0 & 0.33 & 95.6 \\
\hline 300 & 2.861 & 7.18 & 3.60 & 97.9 & 37.0 & 0.33 & 98.7 \\
\hline 400 & 2.864 & 7.27 & 3.62 & 101.5 & 37.6 & 0.34 & 100.3 \\
\hline 600 & 2.870 & 7.36 & 3.65 & 101.8 & 38.1 & 0.34 & 102.0 \\
\hline 800 & 2.875 & 7.40 & 3.66 & 106.2 & 38.5 & 0.34 & 103.0 \\
\hline 1000 & 2.881 & 7.42 & 3.68 & 106.6 & 39.0 & 0.34 & 104.2 \\
\hline
\end{tabular}

The pressure-volume curve determined by the five teste for Blair is shown in Fig. 1. This curve indicates that this dolomite is relatively incompressible with a total volume change of about $4 \%$ at $4 \mathrm{GPa}$. The bulk modulus at $0.1 \mathrm{MPa}$ confining pressure is $10.4 \mathrm{GPa}$ as determined from the initial slope. This modulus increases smoothly to $110 \mathrm{GPa}$ at a pressure of about $1.4 \mathrm{GPa}$. No further change occurs up to pressures of $3.5 \mathrm{GPa}$ (Table 1). In the 1000-MPa range, the value of the bulk modulus is in very good agreement with the ultrasonic value (Table 2). Similar results are shown in Fig. 1 for two additional dolomites ${ }^{9,10}$ : $p_{\mathrm{o}}=2.804$ and $2.769 \mathrm{~g} \mathrm{~cm}^{-3}$. The results for the NTS dolomite $\left(\rho_{0}=2.804\right)$ are in good agreement with the results for Blair, while the results for Upper Bonanza King

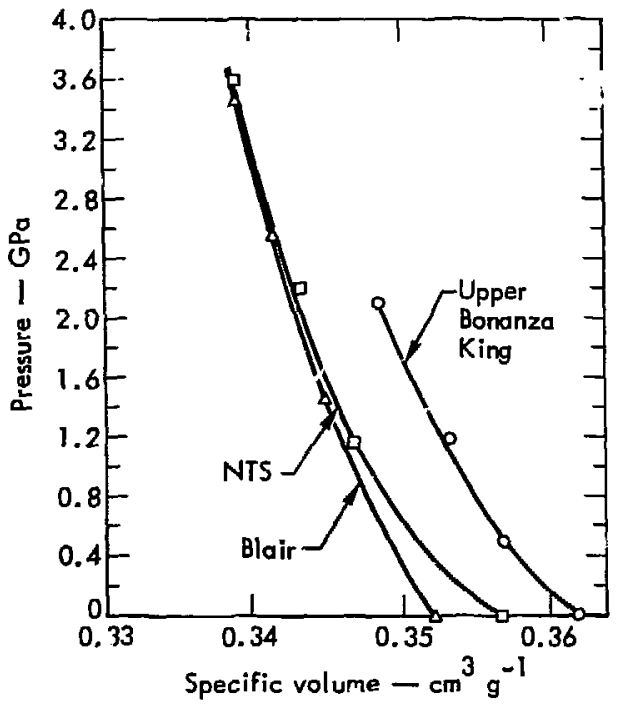

Fig. 2. Pressure vs specific volume for dry Blair $\left(\rho_{0}=2,84\right)$, NTS $\left(\rho_{0}=2.804\right)$, and Upper Bonanza King $\left(\rho_{\circ}=2.769\right)$ dolomites. 
$\left(\rho_{0}=2.769\right)$ material are somewhat diiferent. The small differences in the initial densities ( $<3 \%$ ) of these three dolomites are not enough to account for the different pressure-volume curves. This can be seen in Fig. 2 where the specific volume is plotted as a function of pressure. The NTS and the Blair dolomite curves are nearly identical at high pres- sures, while the Jpper Bonanza King dolomite is still quite different. This difference is probably due to mineralologic differences between the various samples.

The unloading path from $3.5 \mathrm{GPa}$ for. Blair dolomite is the same, within experimental error, as the loading path. After the unloading from $3.5 \mathrm{GPa}$, the total permanent volume change is less than 0.002 .

\section{Uniaxial Stress Measurements (failure)}

Three types of tests were made to delineate the failure behavior of the dry Blair dolomite: uniaxial compression, uniaxial cxtension, and the indirect tension (Brazil) test. The first two types of tests were made on jacketed samples at various pressures, Brazil tests were run at atmospheric pressure only. Using the convention that stress is taken as positive in compression and that $\sigma_{1}, \sigma_{2}, \sigma_{3}$ are the maximum, internediate, and ninimum principal stresses, respectively, uniaxial compression is the case where $\sigma_{1}>\sigma_{2}$ $=\sigma_{3}$. in uniaxial extension, $\sigma_{1}=\sigma_{2}>\sigma_{3}$; in this test, $\sigma_{3}$ may be either positive or negative. The principal stresses are all different in the Brazil test: $\sigma_{1}>\sigma_{2}>\sigma_{3}$. In this case, $\sigma_{3}$ is always negative; that is, it is equal to the tensile strength of the material. Although only atmospheric pressure measurements were made using the Brazil test, the calculated tensile strength is believed to be approximately indeperdent of $\sigma_{2}$, the confining pressure. ${ }^{11}$

Data were taken in the form of forcedisplacement curves. After recalculation to differential stress-axial strain curves, the ultimate strength (in those tests that exhibited brittle behavior) or differential stress taken at 5\% strain (for those experiments that were macroscopically ductile) was noted.

Erittle behavior may be characterized by a sudden change of siop 9 of the stressstrain curve at the y:eld point, followed either by a complete loss of cohesion in the test sample with a subsequent drop of the differential stress to zero, or by continued fracturing and rebealing of the rock, characterized by sharp downward breaks (discontinuities) in the curve. The failure mechanism responsible is a combination of tensile and shear fracturing. Ductile behavior is taken to be the absence of any sharp downwari breaks in slore after the yielr. point, with the sample achieving at least $5 \%$ strain before fracture. On the scale of the test sample, ductile behavior may be the result of homogeneous'y distributed microfractures and the consequent rotation of small elements of the granular material, or by plastic flow (twinnıng or translation) on any scale in the dolomite crystals.

In Fig. 3, we show $\tau$, the shear stress at failure, $\left(\sigma_{1}=\sigma_{3}\right) / 2$, plotted against confining pressure ior the compression, extension, and Brazil tests. Calculations for $T$ 


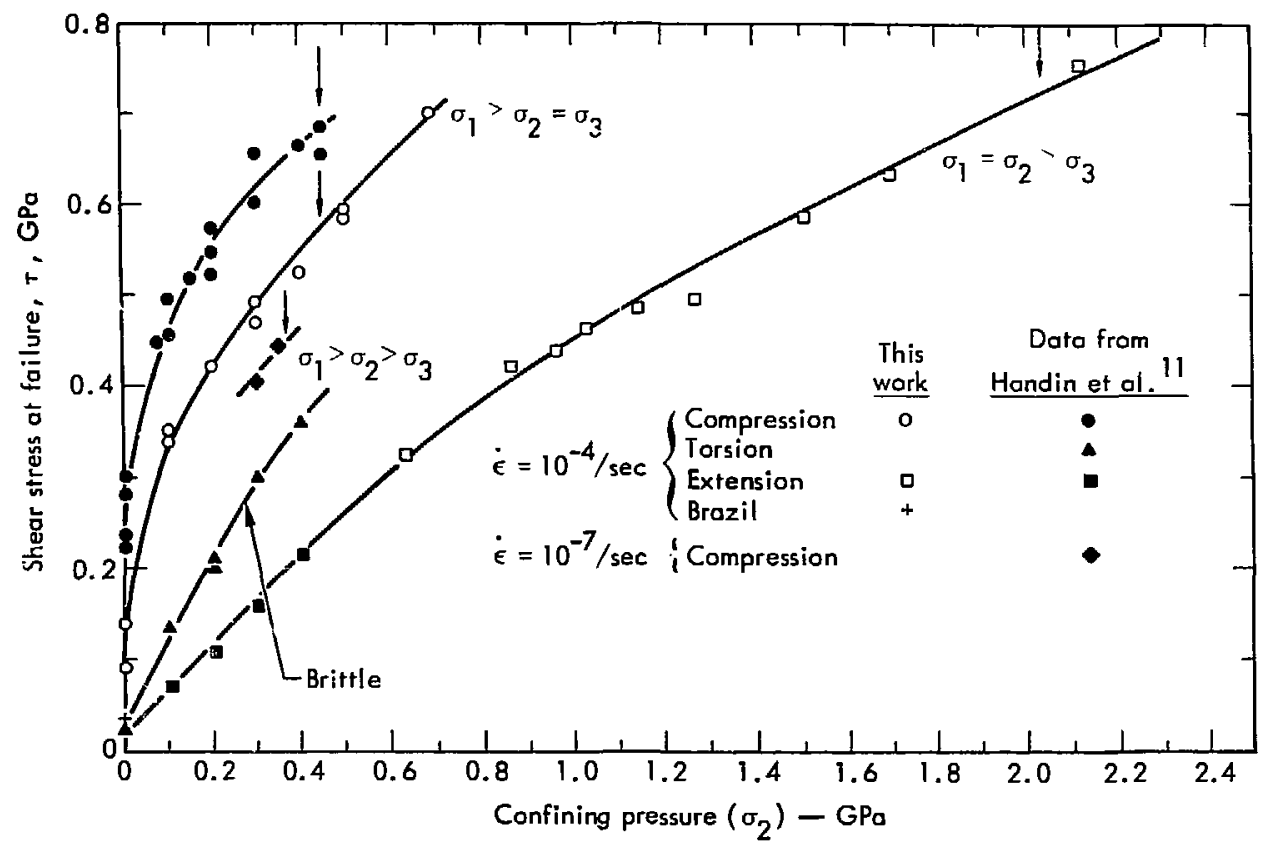

Fig. 3. Shear stress-confining pressure failure envelope for dry Blair dolomite. The compression at low strain rate, the torsion, and a portion of the compression and extension data at low pressure $\left(\dot{\epsilon}=10^{-4} s^{-1}\right)$ are replotted from Handin et al. 11 The arrow indicates the transition from brittle to ductile behavior.

are based on the values for the principal stresses at the failure point on the stressstrain curve as ciscussed above. Many of the tests at pressures up to $0.4 \mathrm{GPa}$ have been replotted from Handin et al. ${ }^{11}$ Note that, in Fig. 3, our results in compression lie slightly lower than Handin's, while our extension data are consistent with his earlier results. The more limited data from Brace ${ }^{12}$ in compression agree with Handin's results at low pressure but diverge at higher pressure to become nearly similar to our data near $0.35 \mathrm{GPa}$. We believe these differences in mechanical response are more likely due to differences between the starting materials than to technique or testing machine calibration.
The position and shape of the compression failure envelope (Fig. 3) are most dependent on the shear strength of the dolomite. In contrast, the intercept and slope of the extension envelope are most affected by the tensile strength - at least up to pressures where $\sigma_{3}$ becomes positive. The average tensile strength from four of our tests is -17.5 MPa. Even in the unlikely case that the tensile strength of Handin's material were larger or smaller by as much as a factor of two, the extension envelope defined by these two sets of data would be expected to je smooth and regular.

In Fig. 3, we also show the $\tau-\sigma_{3}$ curve from Ref. 11 as determined in torsion (hollow test samples). Pure 


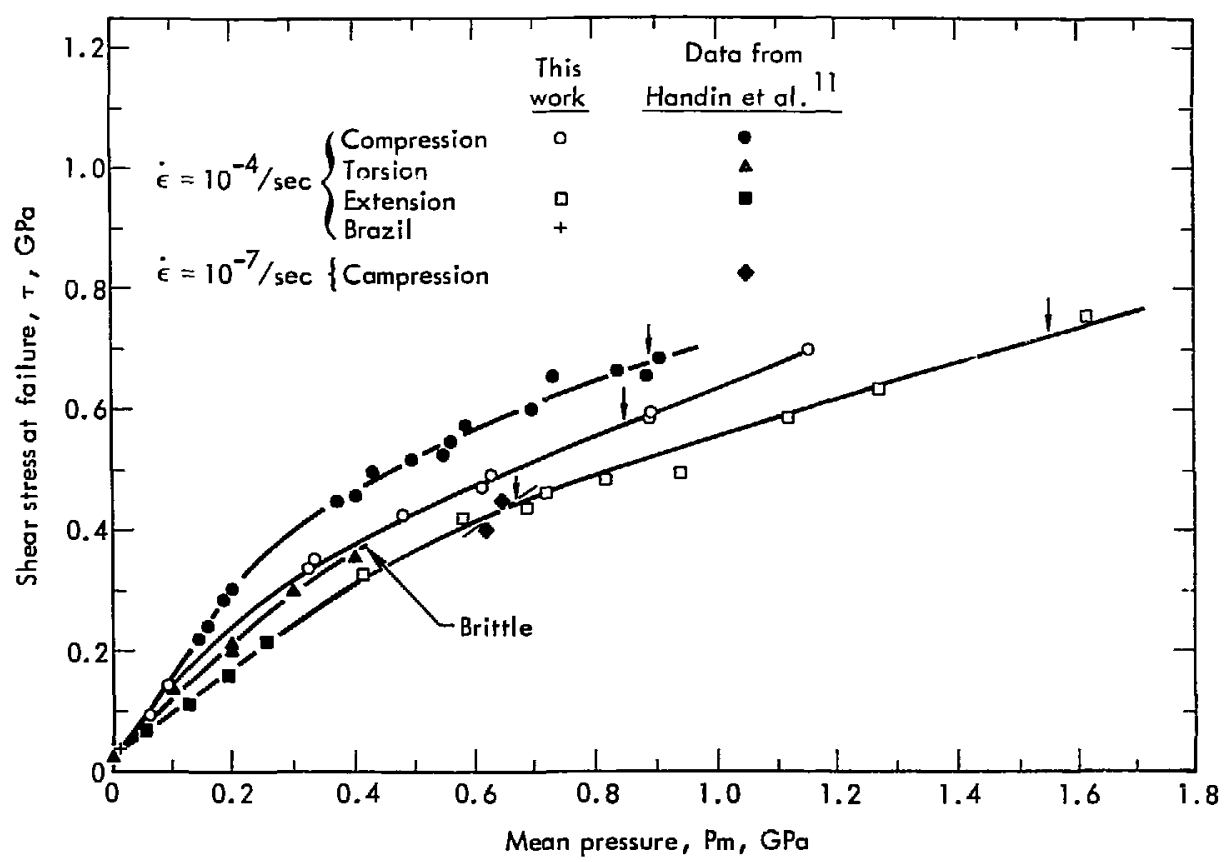

Fig. 4. Shear stress-vs-mean pressure failure envelope for dry Blair dolomite. Replotted from Fig. 2.

torsion under a confining pressure is the intermediate case between compression and extension discussed above. In torsion, $\sigma_{1}>\sigma_{2}>\sigma_{3}$ with $\sigma_{2}$ equal to the confining pressure and exactly midway in value between $\sigma_{1}$ and $\sigma_{3}$. Inspection of Fig. 3 shows clearly that the strength of Blair dolomite at failure is strongly influenced by the relative value of $\sigma_{2}$ compared to $\sigma_{1}$ and $\sigma_{3}$. The brittleductile transition is also quite markedly affected by confining pressure

All of the shear strength results shown in Fig. 3 have been replotted as a function of mean pressure, $P_{m}$, in Fig. 4. Although in this coordinate system the individual failure envelopes are in better agreement than in Fig. 3, there appears to be no unique envelope independent of $\sigma_{2}$. Also, it can be seen that the brittleductile transition pressure is dependent on test type and thus upon $\sigma_{2}$.

All results discussed above were obtained at a strain rate $(\dot{\epsilon})$ of $\sim 10^{-4} \mathrm{~s}^{-1}$. The effect of $\dot{\epsilon}$ on material behavior may be noted by comparing these data with limited data on the Blair dolomite tested in compression but at a much lower strain rate ${ }^{11}: 10^{-7} \mathrm{~s}^{-1}$. Comparison of the two data sets in Figs. 3 and 4 show that the shear strength is lowered about $30 \%$ at a given $\sigma_{3}$ or $P_{m}$. The mean stress at the brittle-ductile transition is similarly lowered (Fig. 4), but the transition pressure, $\sigma_{2}$, is lowered only about $15 \%$ (Fig. 3 ). It is to be expected that these properties would behave similarly for loading in other stress states (i.e., extension). 


\section{Three-Dimensional Stress-Strain Determinations}

Measurements of the three principal stresses as well as the three principal strains have been made over several loading paths on cylindrical samples (20 $\mathrm{mm}$ diam $\times 30 \mathrm{~mm}$ ). Strain gages were used as the sensing elements; these were bonded to $0.25-\mathrm{mm}$-thick lead jackets which prevented penetration of the pressure fluid into the rock pores. Strain gage outputs were corrected for the effects of pressure as outlined by Schock and Duba. ${ }^{13}$ All tests were in compression with the radial stresses $\sigma_{2}$ and $\sigma_{3}$ equal to the confining pressure.
The loading paths investigated included unicxial stress and uniaxial strain. In the former, $\sigma_{3}$ is fixed at some initial value, while $\epsilon_{1}$ and $\epsilon_{3}$ are monitored with increasing $\sigma_{1}$. In the latter test, the radial strains are constrained to remain zero by controlling the confining pressure. Uniaxial strain is the condition thought to represent deformation by a plane shock wave. This test then approximates the conditions prevailing beyond several tens of meters from the source of a nuclear explosion but at very much lower strain rates.

\section{Uniaxial Stress}

Samples were loaded to failure in uniaxial stress at confining pressures of $0.1,20,100,300$, and $500 \mathrm{MPa}$. The measured axial and circumferential strains along this loading path are shown in Fig. 5 for the test at $0.1 \mathrm{MPa}$. The behavior is similar to granitic rocks ${ }^{6,14}$ and to a brittle sanustone ${ }^{15}$ in that the circumferential strain increases linearly (at $\sigma_{1}-\sigma_{3}$ below $100 \mathrm{MPa}$ ) while there is a noticeable nonlinearity in the decrease of axial strain. This is interpreted as due to the closing of long, narrow cracks whose major axes are primarily normal to the axial stress $\left(\sigma_{1}\right)$. At higher values of $\sigma_{1}-\sigma_{3}$ (approaching failure), the circumferential strain is observed to now increase nonlinearly, in contrast to the behavior of the axial strain. This is believed to be the result of the opening or propagation of cracks whose major axes are primarily parallel to $\sigma_{1}$. The effect of this behavior is to increase the macroscopic volume of the rock and is consistent with the dilatancy observed in brittle crystalline rocks. ${ }^{16}$ The associated volume increase

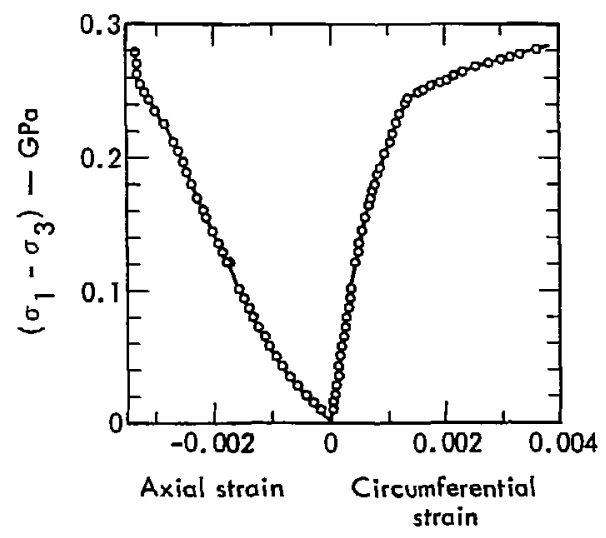

Fig. 5. Axial stress difference vs axial and circumferential strain (confining pressure $\sigma_{3}=0.1 \mathrm{MPa}$ ) for dry Blair dolomite. 


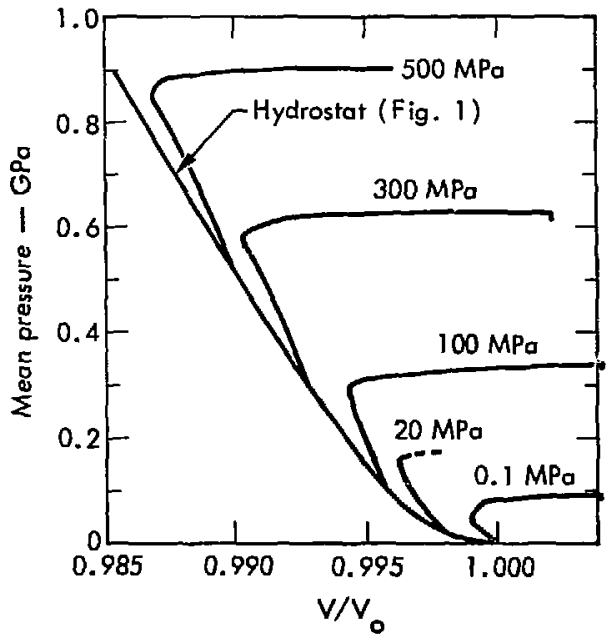

Fig. 6. Mean pressure vs volume strain for dry Blair dolomite. Hydrostat replotted from Fig. 1; uniaxial stress loading paths plotted for the indicated five confining pressures.

is indicated in Fig. 6 , in which $V / V_{0}$ is plotted as a function of mean pressure for the five confining pressures noted above.

At all confining pressures shown in Fig. 6, the compression $\left(V / V_{0}\right)$ in uniaxial stress loading is observed to be less than that at equivalent mean pressures for hydrostatic loading (Figs. 1 and 6). This behavior has not been observed for granitic rocks ${ }^{14}$ but has been observed previously in an isotropic brittle sandstone. ${ }^{15}$ For the sandstone, this behavior was interpreted as due to the response of long, narrow cracks to a superposed differential stress. In that study, the evidence suggested that these cracks (as previously discussed in regard to the data in Fig. 5) were responsible. In hydrostatic compression, $\sigma_{1}=\sigma_{3}$ and cracks of all orientations are equally affected. Initial loading above the hydrostat is still observed for Blair dolomite in uniaxial stress loading at $500 \mathrm{MPa}$. This implies that there are cracks present whose aspect ratio is such that they are either not closed by the confining pressure or are easily opened by the subsequent increase in $\sigma_{1}$.

The slight softening before dilation of the mean pressure $-V / V_{o}$ curves at 300 and $500 \mathrm{MPa}$ confining pressure (Fig. 6) indicates there is some relative compaction before failure. This implies a crushing of porosity and has been reported previously in porous sandstones where irreversible compaction was observed. 17 There it was found to be associated with the transition in failure behavior from brittle failure to ductile flow. Examination of the compression failure data in Fig, 3 shows this transition at about $450 \mathrm{MPa}$ confining pressure, and the data in Fig. 6 would indicate the

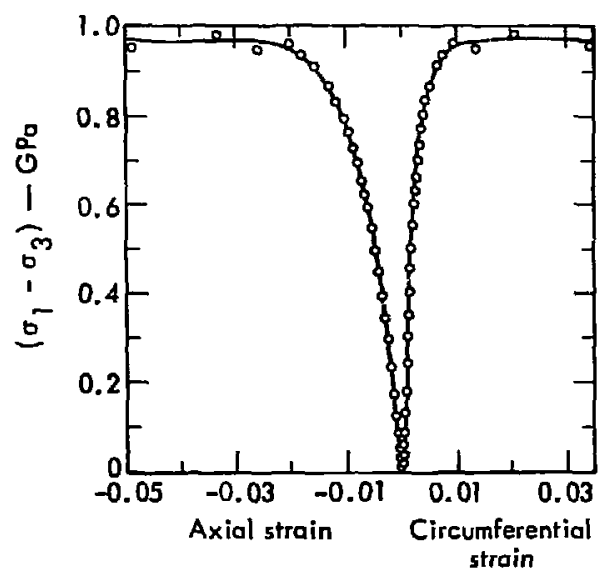

Fìg. 7. Axial stress difference vs axial and circumferential strain (confining pressure $\sigma_{3}=0.3 \mathrm{GPa}$ ) for dry Blair dolomite. 


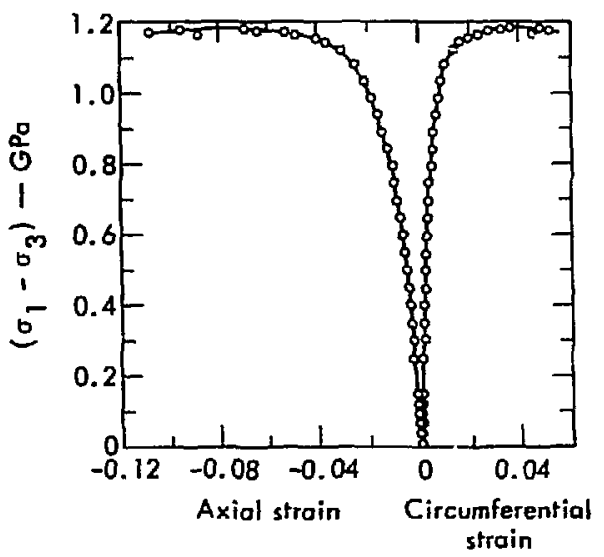

Fig. 8. Axial stress difference vs axial and circumferential strain (confining pressure $\sigma_{3}=0.5 \mathrm{GPa}$ ) for dry Blair dolomite.

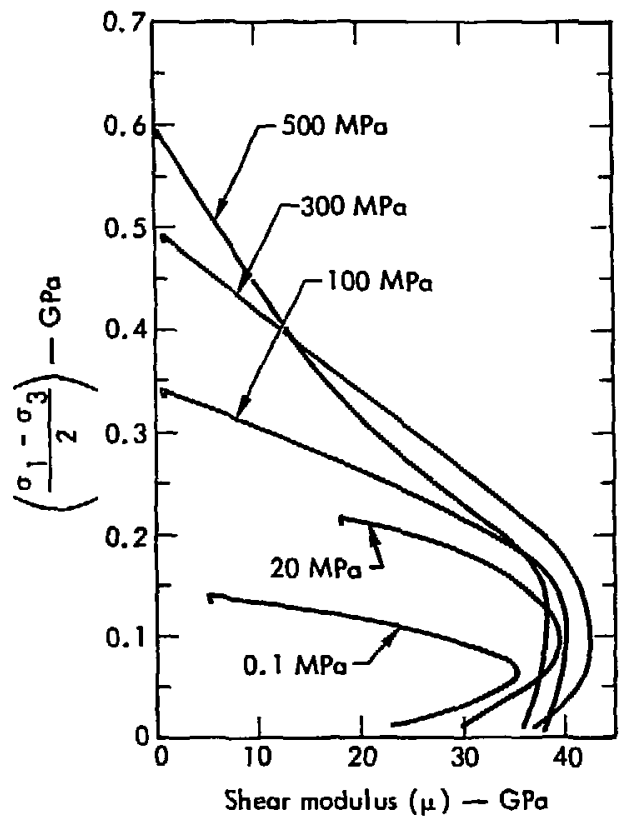

Fig. 9. Shear modulus as a function of shear stress for dry Blair dolomite for uniaxial stress loading at five confining pressures. transition, based on the onset of compaction, to be slightly less than $300 \mathrm{MPa}$. The axial stress-strain curve also indicates some increase in ductility belore failure. A plot of axial strain vs axial stress difference at 300 MPa confining pressure (Fig. T) reveals that the material is transitional between brittle and ductile behavior as defined by Heard. 18 At $500 \mathrm{MPa}$ confining pressure (Fig. B), ductile behavior is evident.

Figure 9 shows the variation of the shear modulus $(\mu)$ with shear stress for each of the tests shown in Fig. 6. This plot shows the second derivative of the shear stress with respect to shear strain. At all pressures in Fig. 9, the shear modulus increases upon the initial application of axial stress. This increase is most prominent for the unconfined sar.ple. Initial increases in the shear modulus as shown in Fig. 9 are consistent with sliding along cracks upon initial application of stress. The effect of slippage along cracks is to decrease the shear modulus with respect to that of the rock without cracks. Once this movement has taken place, the shear modulus stiffens to the intrinsic value. The observation that some stiffening is still occurring at $500 \mathrm{MPa}$ is further evidence that cracks still persist in this rock at these confining pressures.

At higher values of shear stress, as the rock dilates (Fig. 6), $\mu$ (Fig. 9) is observed to decrease as cracks are now opened and microfracturing takes place, leading ultimately to failure. In this rock one may use $\mu$ as a more sensitive indication of dilatancy than the conventional volume strain behavior as typified by granites ${ }^{6}$ since, as previously 
discussed, the uniaxial stress loading in this rock is always above the hydrostat. The non-linear increase in circumferential strain associated with the onset of dilatant behavior will give rise to a rapid increase in shear strain for a given shear stress increment and a resulting decrease in shear modulus.

\section{Uniazial Strain}

Figure 10 compares the typical loading path in uniaxial strain with the failure envelope determined from the uniaxial compression tests (Fig. 3). The tendency of the Blair dolomite to deviate from the failure surface is similar to the behavior of many rocks investigated in this laboratory. $6,14,15,17$

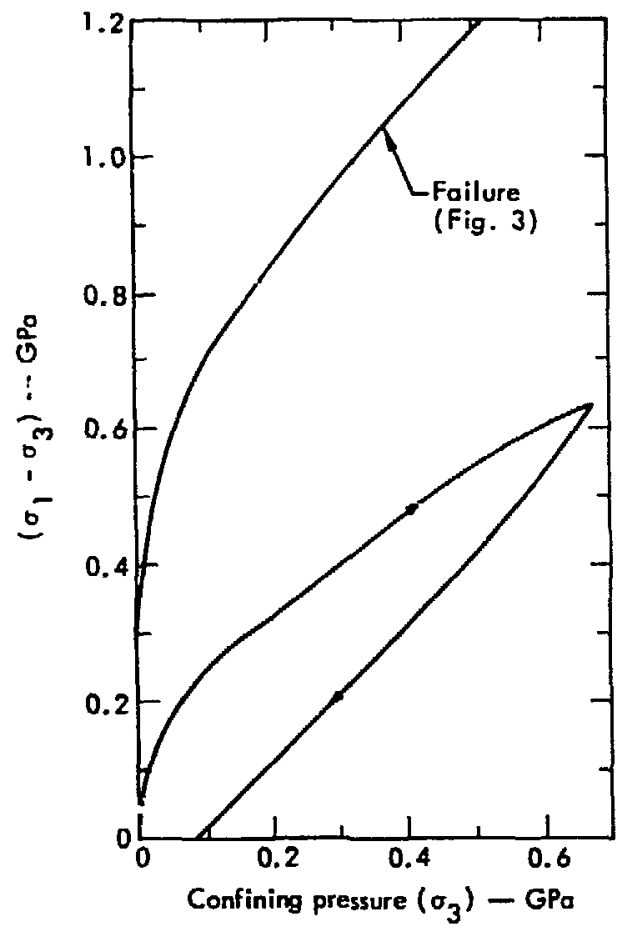

Fig. 10. Uniaxial strain loading path for dry Blair dolomite. Failure envelope replotted from Fig. 3.
Figure 11 compares volume strain measured under uniaxial strain loading with that measured under hydrostatic conditions (FIg. 1). Both axial stress $\left(\sigma_{1}\right)$ and mean pressure $\left(P_{m}\right)$ are included. The $P_{m}$ curve loads above the hydrostat up to about $0.5 \mathrm{MPa}$ and continues below it at all higher pressures. The initial loading above the hydrostat is interpreted as due to unidirectional crack closure as proposed above to explain similar behavior on loading in uniaxial stress. Loading below the hydrostat at higher stresses is

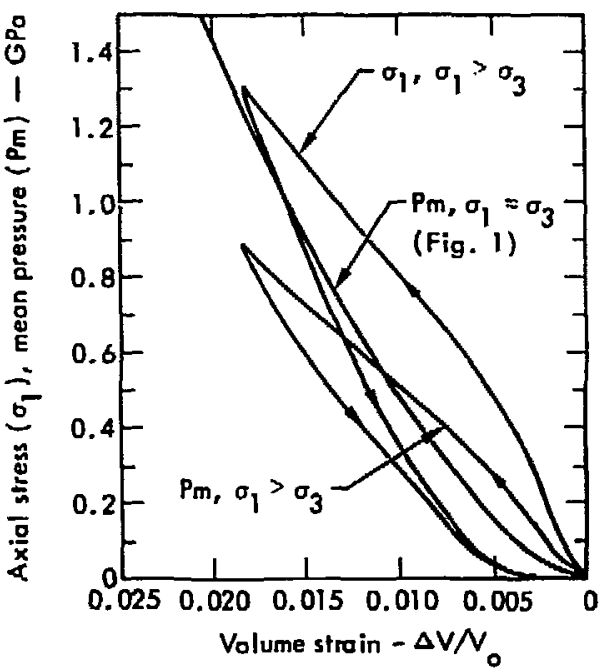

Fig. 11. $\sigma_{1}, P_{m}$ vs volume strain for uniaxial strain loading for dry Blair dolomite. Hydrostat replotted irom Fig. 1. 
evidence of enhanced compaction due to shear stress, ${ }^{6}$ again consistent with the interpretation of the uniaxial stress data (Fig. 6).

On unloading from in axial stress of $1.3 \mathrm{GPa}$ (Fig. 11), the dolomite shows a permanent compaction of 0.003 . This is in reasonable agreement with the permanent $\Delta V / V_{0}$ observed on unloading from 3.5 GPa hydrostatic pressure and suggests that mean pressures of $0.9 \mathrm{GPa}_{\text {, }}$ in the presence of a significant shear stress, are sufficient to remove a majority of the porosity. This assumes that all porosity is removed by $3.5 \mathrm{GPa}$.

The effective shear modulus on initial loading in uniaxial strain (Figs. 10 and 11 ) is $25.7 \mathrm{GPa}$. This compares favorably with the value of $23.1 \mathrm{GPa}$ obtained from the initial uniaxial stress loading it Fig. 5. The initial effective bulk modulus from the data in Figs. 10 and 11 is $22.2 \mathrm{GPa}$, compared with 25.0 GPa obtained on uniaxial stress loading. At $30 \mathrm{MPa}$ axial stress difference (Fig. 10), the effective shear modulus has increased to $19.0 \mathrm{GPa}$. As deformation proceeds, the shear modulus decreases to $10.0 \mathrm{GPa}$ in the vicinity of the maximum axial stress difference of $63 \mathrm{MPa}$. The effective bulk modulus at this point is $50.0 \mathrm{GPa}$. In uniaxial strain loading, the bulk modulus of this dolomite increases while the shear modulus decreases, a behavior similar to many rocks. 15,17 Consequently, the effective Poisson's ratio then increases with deformation.

\section{Acoustic Velocity Determinations}

Acoustic velocities were determined to 1.0 GPa hydrostatic pressure on the Blair dolomite using experimental and data reduction techniques described earlier. ${ }^{8}$ Briefly, the travel time of a $1-\mathrm{MHz}$ wave through a $30-\mathrm{mm}$ length of rock is measured as a function of confining pressure. The derived elastic bulk modulus is integrated as a function of pressure to compute the shange in sample length and density with pressure. The shear velocities were determined from travel-time measurements using $\mathrm{Pb}\left(\mathrm{Zr}, \mathrm{Ti}_{3}\right.$ piezoelectric transducers. Since these transducers are not mode pure, the shear velocity measurement was compared at atmospheric pressure $w i$ th that determined using mode pure, A-C cut quartz crystals. The excellent agreement between the quartz and the PZT transducers
( 3.03 vs $3.02 \mathrm{~km} \mathrm{~s}^{-1}$ ) indicates that the shear wave velocities determined from the mixed-mode signal are correct.

Figures 12 and 13 display the observed travel-times for both the compressional

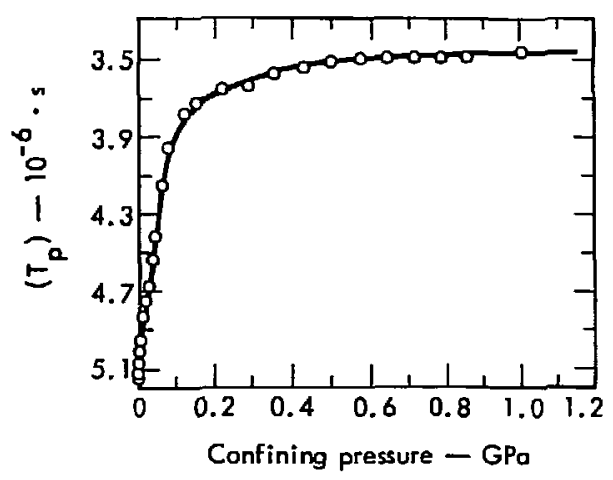

Fig. 12. Compressional wave travel time $\left(T_{p}\right)$ vs pressure for dry Blair dolomite. 


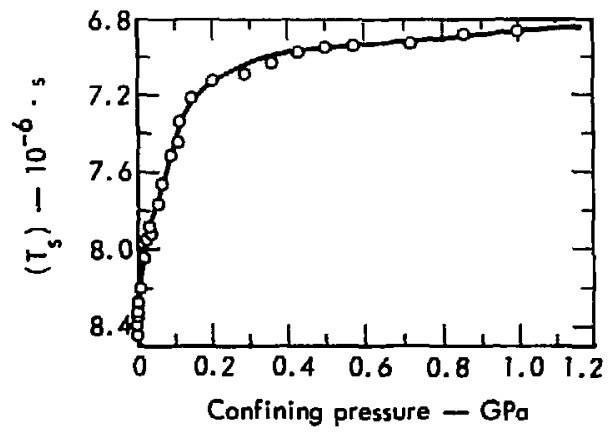

Fig. 13. Shear wave travel time $\left(T_{S}\right)$ vs pressure for dry Blair dolomite.

and shear waves as a function of pressure. The computed velocities and derived moduli are listed in Table 2. The largest change in velocities and moduli occurs in the first $100 \mathrm{MPa}$, probably because of the closing of most cracks by pressure. ${ }^{6,14}$ The small increase in velocities above this pressure indicates closure of additional cracks, However, their volume fraction is small compared to that below $100 \mathrm{MPa}$.

The compressional velocity calculated from the uniaxial strain data (assuming elasticity! in Figs. 10 and 11 are $4.45 \mathrm{~km} \mathrm{~s}^{-1}$ on initial loading and $7.21 \mathrm{~km} \mathrm{~s}^{-1}$ after the stiffening of the $\sigma_{1}-\Delta V / V_{0}$ curve in Fig. $11\left(P_{m}\right.$ - 10-15 MPa). These values should then agree with observed shock velocities in the elastic region. The initial value compares well with the value of $5.02 \mathrm{~km} \mathrm{~s}^{-1}$ determined ultrasonically in the laboratory at $0.1 \mathrm{MPa}$ (see Table 2), when one considers the effect of cracks on dynamicvs-static moduli. ${ }^{19}$ At axial stresses above $100 \mathrm{MPa}$, when some of these cracks close, the agreement becomes much better (compare 7.21 with $7.00 \mathrm{~km} \mathrm{~s}^{-1}$ at $200 \mathrm{MPa}$ in Table 2).

\section{Acknowledgments}

E. Joslyn, H. Louis, and H. Washington assisted in obtaining the data presented here. 


\section{References}

1. L Graf, Am. Min. 16 , 1283 (1961).

2. D. R. Stephens, E. M. L.illey, and H. Louis, Int. J. Rock Mech. Min. Sci. ?. 257-296 (1970).

3. D. R. Stephens and E. M. Lilley, Geochim. et Cosmochim. Acta. Supple. 2 3 , 2165-2176 (1971).

4. J. Handin and R. V. Hager, Jr., Amer. Assoc. Petrol. Geol. Bull. 4l. 1 (1957).

5. H. C. Heard, "Transition from Brittle to Ductile Flow in Solenhofen Limestone as a Function of Temperature, Confining Pressure and Fluid Pressure," in Rock Deformation, Memoir 79, Griggs and J. Handin, Eds. (Geological Society of America, Boulder, Colorado, 1960).

6. R. N. Schock, H. C. Heard, and D. R. Stephens, J.Geophys. Res, 78, 5922 (1973).

7. R. N. Schock and A. G. Duba, J. Appl. Phys. 43, 2204 (1972).

8. R. N. Schock, H. Louis, and E. Lilley, Determination of Acoustic Velocities and Dynamic Elastic Moduli in Rocks Under Pressure, Lawrence Livermore Laboratory, Rept. UCRL-50750 (1969).

9. D. R. Stepinens, J. Geophys. Res. 69, 2967 (1964).

10. D. R. Stephens, E. M. Lilley, and H. Louis, Pressure-Volume Equation of State of Consolidated and Fractured Rocks to 40 Kbar, Lawrence Livermore Laboratory, Rept. UCRL-71238 (1969).

11. J. Handin, H. C. Heard, and J. N. Magouirk, J. Geophys. Res. 72, 611 (1967).

12. W. F. Brace, "Brittle Fracture of Rocks," in State of Stress in the Earth's Crust, W. R. Judd, Ed. (American Elsevier, N. Y., 1964), pp. 111-174.

13. R. N. Schock and A.G. Duba, Exp1. Mech. 13, 43 (1973).

14. P. N. Shock, A. E. Abey, H. C. Heard, and H. Louis, Mechanical Properties of Granite from the Taourist Tan Afalla Massif, Algeria, Law rence Livermore Laboratory, Rept. UCRL-51296 (1972).

15. R. N. Schock, A. E. Abey, B. P. Bonner, A. Duba, and H. Heard, Mechanical Properties of Nugget Sandstone, Lawrence Livermore Laboratory, Rept. UCRL-51447 (1973).

16. W. F. Brace, B.W. Paulding, and C. Scholz, J. Geophys, Res. 71, 3939 (1966).

17. R. N. Schock, H.C. Heard, and D.R. Stephens, Comparison of the Mechanical Properties of Graywacke Sandstones from Several Gas Stimulation Sites,

Lawrence Livermore Laboratory, Rept. UCRL-51261 (1972).

18. H. C. Heard, "The Influence of Envizonment on the Inelastic Behavior of Rocks," Proceedings of Symposium on Engineering with Nuclear Explosives, ANS, Las Vegas, 1970, pp. 127-141.

19. G. Simmons and W. F. Brace, J. Geophys. Res. 그, 5649 (1965). 